Revista Energia na Agricultura

ISSN 1808-8759

\title{
EFEITO IMEDIATO DO MÉTODO DE SECAGEM NA QUALIDADE DE SEMENTES DE CRAMBE ${ }^{1}$ ANA CRISTINA ENSINAS DE OLIVA ${ }^{2}$; MARCO ANTONIO MARTIN BIAGGIONI ${ }^{3}$ \& CLÁUDIO CAVARIANI $^{4}$
}

RESUMO: O crambe (Crambe abyssinica Hochst) é uma cultura que se destaca pelo elevado teor de óleo de suas sementes, sendo, atualmente, estudada no Brasil visando a produção de biodiesel. Com o início da produção comercial de suas sementes no país, surgiu a necessidade de pesquisas na área de tecnologia e produção. Independentemente do nível tecnológico empregado na produção de uma cultura é essencial a utilização de sementes de boa qualidade. Dentre vários fatores que afetam a qualidade das sementes, destaca-se o processo de secagem. A secagem das sementes realizada de maneira adequada permite reduzir o grau de umidade das sementes para o armazenamento sem alterar suas características qualitativas. $\mathrm{O}$ objetivo deste trabalho foi verificar o efeito imediato da secagem natural e artificial (com ar aquecido e não aquecido) sobre a germinação de sementes de crambe. Para isto, foi instalado um campo experimental de produção de sementes de crambe na Fazenda Experimental Lageado, pertencente à Faculdade de Ciências Agronômicas, UNESP, no município de Botucatu, em 2009. Os tratamentos realizados foram: secagem das sementes à sombra com ventilação natural, secagem artificial com ar aquecido, secagem artificial com ar não aquecido, secagem em terreiro e secagem na planta. As sementes foram avaliadas logo após a secagem, por meio da determinação do teor de água, teste de germinação, primeira contagem da germinação, emergência de plântulas, índice de velocidade de emergência e condutividade elétrica. $\mathrm{O}$ delineamento experimental foi em blocos ao acaso; os dados obtidos foram submetidos à análise de variância e as médias comparadas pelo teste de Tukey a 5\% de probabilidade. Não houve diferença significativa entre os tratamentos de secagem estudados quanto à porcentagem de germinação, primeira contagem, condutividade elétrica, emergência de plântulas e índice de velocidade de emergência de plântulas. A maior porcentagem de plântulas anormais foi obtida no tratamento de secagem com ar aquecido, e o método de secagem na planta apresentou menor porcentagem de sementes mortas. De acordo com os resultados, os métodos

\footnotetext{
${ }^{1}$ Parte da dissertação da $1^{\text {a }}$ autora intitulada: Qualidade de sementes de crambe submetidas a métodos de secagem e períodos de armazenamento.

${ }^{2}$ Aluna do curso de PG Energia na Agricultura-FCA/UNESP, Fazenda Experimental Lageado, Rua José Barbosa de Barros - 1780, Caixa Postal - 237 Botucatu-SP - Brasil; CEP 18610-307 email: aceoliva@gmail.com

${ }^{3}$ Orientador e docente do Departamento de Engenharia Rural FCA/UNESP, Fazenda Experimental Lageado, Rua José Barbosa de Barros - 1780, Caixa Postal - 237, Botucatu-SP - Brasil, CEP 18610-307. e-mail: biaggioni@fca.unesp.br

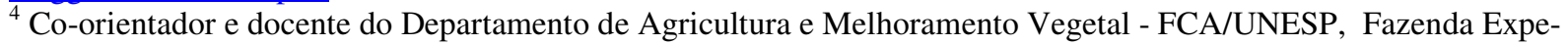
rimental Lageado, Rua José Barbosa de Barros - 1780, Caixa Postal - 237, Botucatu-SP - Brasil, CEP 18610-307. email: ccavariani@fca.unesp.br
} 
de secagem estudados não causaram efeito imediato na qualidade das sementes de crambe, que apresentaram elevada porcentagem de sementes dormentes após a colheita.

Palavras-chaves: Crambe, secagem, dormência, germinação.

\section{IMMEDIATE EFFECT OF DRYING METHODS ON CRAMBE SEEDS QUALITY}

SUMMARY: Crambe (Crambe abyssinica Hochst) seeds have high oil contents and its growth in Brazil aims to produce bio diesel. The crambe seeds production and commercialization began a few years ago. Research in technology production is essential and it is also important to use high quality seeds regardless of the technological level employed in the crop production. One of the factors that affect seed quality there is the drying process. Seed drying performed properly can reduce seed moisture content for storage without decrease in its qualitative characteristics. The aim of this study was to evaluate the immediate effect of natural and artificial drying methods (using heated and unheated air) on crambe seeds quality. The seeds were produced at Fazenda Lageado, Faculdade de Ciências Agronômicas, UNESP, Botucatu/SP, on April 2009. Seeds were submitted to the following drying methods: a) seed drying in the shade with natural ventilation; b) artificial drying method using heated air; c) artificial drying method using unheated air; d) drying on ceramic patio; e) drying on the mother plant. The seeds were evaluated immediately after drying. The following tests were performed: seed moisture content; standard germination; first count of germination; seedling emergence; emergence speed index and electrical conductivity. The experimental design was randomized blocks and the data obtained was subjected to analysis of variance, worth means being compared by Tukey test at 5\% probability. There was no significant difference among drying treatments in relation to: germination rate, first count of germination, electrical conductivity, seedling emergence and emergence speed index. The highest percentage of abnormal seedlings was obtained on treatment with heated air drying. The drying on the mother plant method showed the lower percentage of dead seeds. The drying methods studied did not cause an immediate effect on crambe seeds quality, which showed high percentage of dormant seeds post-harvest.

Keywords: Crambe, drying, dormancy, germination.

\section{INTRODUÇÃO}

O crambe (Crambe abyssinica Hochst) pertencente a família Brassicaceae, é uma cultura que se destaca pelo elevado teor de óleo de suas sementes, sendo, atualmente, estudada no Brasil visando a 
produção de biodiesel. Tem como vantagens o cultivo totalmente mecanizado, utilizando os mesmos equipamentos já existentes para grãos miúdos, e a possibilidade de cultivo no inverno. Por ser uma cultura pouco conhecida comercialmente, praticamente não se dispõe, ainda, de informações técnicas que viabilize seu cultivo intensivo. Com o início da produção comercial de suas sementes no país, surgiu a necessidade de pesquisas na área de tecnologia e produção.

As flores produzem um grande número de sementes pequenas, com conteúdo de óleo aproximado de $40 \%$. O fruto é uma síliqua que contém uma única semente esférica, de cor verde ou marrom esverdeado. O tamanho da semente varia consideravelmente no diâmetro $(0,8$ a 2,6 mm), sendo influenciado pelo número de sementes por planta, fertilidade do solo e chuva (DESAI et al., 1997).

O crambe apresenta hábito de florescimento indeterminado. Para estas plantas, o florescimento e, consequentemente a produção das sementes, ocorrem por um extenso período (COPELAND, 1976).

O florescimento inicia-se da base para as pontas dos ramos e, após esse período, a maturação do crambe ocorre rapidamente (de uma a duas semanas). Os primeiros frutos formados permanecem aderidos à planta até que os últimos frutos tenham atingido a maturidade. Desta forma, sementes em vários estágios de desenvolvimento estão presentes na planta de forma simultânea (FONTANA et al., 1988).

No momento em que cessa a transferência de matéria seca da planta para as sementes, estas apresentam potencial fisiológico elevado, senão o máximo (MARCOS FILHO, 2005). A maturação excessiva destas sementes na planta-mãe pode ser prejudicial à qualidade da semente. Em sementes que secam naturalmente no estádio para a colheita, a maturação excessiva não tem significado de desenvolvimento e, se estas não forem colhidas de imediato, o envelhecimento e a deterioração podem ocorrer (CASTRO et al., 2004).

A secagem é uma operação que possibilita antecipar a colheita e permite a obtenção de sementes de melhor qualidade. Desta forma, é possível evitar o armazenamento no campo e danos que ocorrem devido as condições climáticas, ataques de insetos, microorganismos, etc. diminuindo o teor de água a níveis tais que diminuem o efeito ou ataque dos insetos e dos microorganismos, e reduzem a taxa de deterioração das sementes durante o armazenamento (CARVALHO; NAKAGAWA, 2000).

A escolha do método de secagem a que as sementes serão submetidas depende da espécie, da estrutura e equipamentos disponíveis, do volume de sementes e dos mecanismos que possam reduzir os custos operacionais, diminuir o tempo de secagem e a energia consumida.

A secagem de sementes em terreiro é simples e de baixo custo, porém exige mão-de-obra operacional e baixo volume de material, além de depender das condições climáticas. A secagem artificial das sementes, utilizando ventilação com ar em temperatura ambiente, preserva a qualidade das mesmas, porém pode necessitar um prolongado período de tempo, enquanto a utilização do ar aquecido à temperatura adequada possibilita reduzir o teor de água das sementes em menor tempo. 
É importante saber quando a retirada de água das sementes causa perda na viabilidade e no vigor e muitos trabalhos relatam danos quando as sementes são secas a $5 \%$ ou menos de conteúdo de água. Sementes de algumas espécies que podem ser secas a um conteúdo de água de 2 a $3 \%$ sofrem injúrias quando secas a $1 \%$ ou menos, sendo que o primeiro indicador de injúria é a redução na taxa de germinação. Com uma secagem drástica, os sintomas de injúria aparecem imediatamente após a secagem (JUSTICE; BASS, 1978).

Sementes de canola não têm sua qualidade fisiológica prejudicada quando submetidas à secagem à $30{ }^{\circ} \mathrm{C}$, independente da umidade relativa do ar, tanto imediatamente quanto após 120 dias de armazenamento. Porém, ocorre um decréscimo no vigor e na germinação com o aumento da temperatura de $30^{\circ} \mathrm{C}$ até $60^{\circ} \mathrm{C}$ e decréscimo da umidade relativa do ar de $60 \%$ até $30 \%$ (CHRIST et al., 1997).

Muitas sementes ortodoxas podem sobreviver à secagem lenta quando se encontram no início da fase de maturação, mas não toleram secagem rápida (HONG; ELLIS, 1992 citado por HAY; PROBERT, 1995). Tanto em sementes silvestres como em sementes de espécies cultivadas, as quais são colhidas com alto teor de água, é possível que a secagem rápida comprometa tanto a viabilidade (em indivíduos que não tenham adquirido a tolerância à dessecação) como a longevidade durante o armazenamento (HAY; PROBERT, 1995).

A dessecação prematura afeta a síntese de proteínas, bem como a de enzimas essenciais ao desenvolvimento e à germinação; assim a remoção das sementes da planta e sua secagem rápida podem determinar a perda completa da viabilidade, dependendo do estádio de desenvolvimento em que for efetuada (MARCOS FILHO, 2005).

A viabilidade é um fator importante a ser mantido durante a secagem e armazenamento das sementes, o qual as sementes podem perder rapidamente quando submetidas a secagem com ar aquecido em temperaturas excessivas ou quando armazenadas com conteúdo de água elevado (COPELAND, 1976).

A secagem é fundamental para o processo produtivo e demanda conhecimentos específicos para cada espécie, para que a qualidade das sementes não seja afetada. Assim sendo, objetivou-se neste trabalho verificar o efeito imediato da secagem natural e artificial (com ar aquecido e não aquecido) sobre a germinação de sementes de crambe.

\section{MATERIAL E MÉTODOS}

O trabalho foi desenvolvido na Faculdade de Ciências Agronômicas - FCA, Campus de Botucatu/UNESP. Para a obtenção de sementes de crambe, foi instalado um campo de produção na Fazenda Experimental Lageado, em uma área quem tem como coordenadas geográficas aproximadas Latitude $22^{\circ} 51^{\prime}$ S e Longitude $48^{\circ} 26^{\prime} \mathrm{W}$ de Greenwich, altitude média de 770 metros, declividade média de 4,5\% e clima 
subsubtropical, apresentando verões quentes e úmidos e invernos frios e secos, tipo CWa, de acordo com a classificação de Köeppen. Os tratamentos de secagem foram conduzidos no Laboratório de Processamento de Produtos Agrícolas pertencente ao Departamento de Engenharia Rural e na Fazenda Experimental Lageado, e as análises foram realizadas no Laboratório de Análise de Sementes pertencente ao Departamento de Produção Vegetal - Setor Agricultura.

Adotou-se delineamento experimental em blocos ao acaso com seis repetições para os tratamentos de secagem à sombra, secagem com ar não aquecido, secagem em terreiro, secagem no campo e quatro repetições para o tratamento de secagem com ar aquecido, devido a diferenças na capacidade dos secadores utilizados.

O campo experimental para a produção de sementes de crambe foi semeado sob Sistema de Plantio Direto, sem a pré-definição de parcelas, ou seja, o campo foi semeado continuamente, sendo que os blocos foram definidos e demarcados no local somente no momento próximo a realização da colheita. A área foi dessecada no dia 15 de abril de 2009, utilizando-se 5L ha ${ }^{-1}$ do herbicida Roundup Original (glyphosate $360 \mathrm{~g} \mathrm{~L}^{-1}$ ).

Para a semeadura, foram utilizados $22 \mathrm{~kg} \mathrm{ha}^{-1}$ de sementes básicas de crambe da cultivar FMS Brilhante, fornecidas pela Fundação Mato Grosso do Sul, previamente tratadas com $250 \mathrm{ml} .100 \mathrm{~kg}^{-1} \mathrm{de}^{\mathrm{a}}$ sementes do fungicida Vitavax-Thiram $200 \mathrm{SC}$ (carboxina $200 \mathrm{~g} \mathrm{~L}^{-1}+$ tiram $200 \mathrm{~g} \mathrm{~L}^{-1}$ ). A semeadura foi realizada no dia 17 de abril de 2009, com espaçamento de $17 \mathrm{~cm}$ entre linhas, com uma semeadoraadubadora de fluxo contínuo, marca Semeato, modelo SHM.

$\mathrm{Na}$ adubação no sulco de semeadura aplicou-se 24,5 $\mathrm{kg} \mathrm{ha}^{-1}$ de nitrogênio, 85,7 $\mathrm{kg} \mathrm{ha}^{-1}$ de fósforo e $49 \mathrm{~kg} \mathrm{ha}^{-1}$ de potássio, utilizando-se $306 \mathrm{~kg} \mathrm{ha}^{-1}$ do formulado comercial N-P-K (08-28-16) marca Fertipar. Aplicou-se na adubação de cobertura, realizada 23 dias após a semeadura, $45 \mathrm{~kg} \mathrm{ha}^{-1}$ de nitrogênio, utilizando-se $100 \mathrm{~kg} \mathrm{ha}^{-1}$ de uréia também da mesma marca.

Devido à precipitação pluvial na área durante o desenvolvimento da cultura e à alta umidade relativa do ar, propícias ao surgimento de doenças fúngicas, foram realizadas duas aplicações do fungicida comercial Folicur 200 EC (Tebucinazole $200 \mathrm{~g} \mathrm{~L}^{-1}$ ) aos 50 e 60 dias após a semeadura.

$\mathrm{O}$ teor de água das sementes produzidas foi monitorado ao final do processo de maturação para determinar o dia da colheita, a qual foi realizada em duas etapas: a primeira, referente às parcelas destinadas aos tratamentos de secagem das sementes à sombra com ventilação natural, secagem com ar aquecido, secagem com ar não aquecido e secagem natural em terreiro, quando o teor de água médio das sementes correspondeu a $19,9 \%$; e a segunda, referente ao método de secagem na planta, quando o teor de água médio das sementes correspondeu a $11,6 \%$. 
Ambas as colheitas foram realizadas mecanicamente com colhedora autopropelida de grãos, marca Massey Ferguson, modelo MF 1630, dotada de plataforma de corte com 3,9 m de largura, com picadordistribuidor de palha, com regulagem apropriada para cada situação.

Após a primeira colheita, realizada aos 130 dias após a semeadura, as sementes foram levadas em sacos de ráfia para os respectivos locais onde foram submetidas aos métodos de secagem descritos a seguir e, após a secagem, foram armazenadas em sacos de papel unifoliado para posterior limpeza e avaliação. Ao término da segunda colheita, realizada aos 136 dias após a semeadura, as sementes também foram levadas em sacos de ráfia para laboratório e transferidas para sacos de papel unifoliado, para limpeza e avaliação. Foi utilizada peneira da marca Granutest, abertura $2,38 \mathrm{~mm}$, número 8 (ABNT), para eliminação de sementes miúdas, quebradas e impurezas, e soprador de sementes modelo South Dakota, marca DeLeo, com $6 \mathrm{~cm}$ de abertura na saída de ar do tubo acrílico, durante 1 minuto, para retirada de sementes chochas e outras impurezas. Em seguida, iniciou-se a avaliação da germinação de todos os tratamentos.

Os tratamentos de secagem artificial das sementes de crambe colhidas na primeira etapa foram:

Secagem à sombra com ventilação natural - as sementes das seis repetições originadas no campo de produção foram espalhadas separadamente em camada delgada, com espessura de apenas uma única semente, sobre lona plástica e mantidas sob telhado, com ventilação natural, de forma que as sementes permaneceram à sombra durante o dia e protegidas do sereno durante à noite.

Secagem artificial com ar aquecido - ocorreu em um secador desenvolvido na Faculdade de Ciências Agronômicas - UNESP, destinado à pesquisa. As quatro colunas de PVC de 0,8 $\mathrm{m}$ de altura e 0,15 m de diâmetro, com uma tela metálica no fundo, abrigaram as quatro repetições originadas dos blocos do campo experimental. A altura da massa de grãos em cada coluna foi de 0,60 metros, e o ar de secagem foi insuflado no sistema por meio de um ventilador acionado por um motor elétrico. O aquecimento do ar foi promovido por uma resistência elétrica, proporcionando, por meio de um termostato, a regulagem da temperatura. A temperatura média do ar de secagem, medida por meio de um termômetro analógico localizado no duto da entrada do ar no secador, foi de $45,5^{\circ} \mathrm{C}$ e a temperatura média da massa de sementes foi de $39,7^{\circ} \mathrm{C}$. No final da secagem, a temperatura do ar e, em conseqüência a da semente, foi reduzida gradativamente, permitindo a passagem do fluxo de ar pelas sementes à temperatura ambiente por 30 minutos, visando minimizar a ocorrência de danos térmicos à semente. O fluxo de ar médio de secagem foi de $217,3 \mathrm{~m}^{3} \cdot \mathrm{min}^{-1} \cdot \mathrm{t}^{-1}$ e a e umidade relativa média do ar de secagem foi de $18,9 \%$.

Secagem com ar não aquecido - ocorreu em um secador desenvolvido na Faculdade de Ciências Agonômicas - UNESP, destinado à pesquisa. As seis colunas de PVC de 1,5 m de altura e 0,15 m de diâmetro, com uma tela metálica no fundo, abrigaram as seis repetições originadas dos blocos do campo experimental. A altura da massa de grãos em cada coluna foi de 1,25 metros. A temperatura média do ar de secagem, medida por meio de um termômetro analógico localizado no duto da entrada do ar no secador, 
foi de $24,0{ }^{\circ} \mathrm{C}$ e a temperatura média da massa de sementes foi de $21,0{ }^{\circ} \mathrm{C}$. O fluxo de ar médio de secagem foi de $25,7 \mathrm{~m}^{3} \cdot \mathrm{min}^{-1} \cdot \mathrm{t}^{-1}$ a e umidade relativa média do ar de secagem foi de $61,2 \%$.

Secagem em terreiro - foi realizada na FEPP - Fazendas de Ensino, Pesquisa e Produção, pertencente à Faculdade de Ciências Agronômicas. As sementes foram espalhadas em terreiro de tijolo maciço, numa camada de 5 centímetros de espessura. As sementes foram revolvidas durante o dia com um rastelo de madeira, de forma a posicionar as pequenas leiras formadas no sentido da sombra, expondoas sementes de melhor maneira ao sol. Ao entardecer, as sementes eram juntadas e cobertas com lona plástica.

O tratamento de secagem natural das sementes de crambe colhidas na segunda etapa foi:

Secagem na planta - as parcelas destinadas a este tratamento permaneceram no campo até a colheita aos 136 dias após a semeadura. Neste momento, o teor de água das foi de 11,6\%.

Para todos os tratamentos foi determinado o tempo de secagem e teor de água das sementes no início e ao final do tratamento de secagem pelo método da estufa a $105 \pm 3^{\circ} \mathrm{C}$ (BRASIL, 1992).

Avaliação das sementes foi realizada por meio da determinação do teor de água, teste de germinação seguido do teste de tetrazólio, a fim de verificar a viabilidade das sementes classificadas como dormentes ao final do teste, primeira contagem, emergência de plântulas, índice de velocidade de emergência e condutividade elétrica.

O teor de água das sementes foi determinado no momento da instalação do teste de germinação, pelo método da estufa a $105 \pm 3^{\circ} \mathrm{C}$, por 24 horas, utilizando-se duas repetições de 4,5 $\pm 0,5$ gramas (BRASIL, 1992), com resultados expressos em porcentagem (base úmida).

Para a germinação foram utilizadas quatro repetições de 50 sementes cada, distribuídas sobre papel substrato mata borrão, Germibox, colocado dentro de caixas plásticas transparentes e umedecido com quantidade de água equivalente a 2,5 vezes a massa do papel seco, e então colocadas para germinar em temperatura alternada de $20-30^{\circ} \mathrm{C}$, iluminadas durante 8 horas a cada ciclo de 24 horas. A contagem de plântulas foi realizada aos 4 e 7 dias após a instalação do teste (BRASIL, 2009), com resultados expressos em porcentagem.

A viabilidade das sementes classificadas como dormentes ao final do teste de germinação foi verificada pelo teste de tetrazólio. Para isto, as sementes foram colocadas em copos plásticos de $50 \mathrm{~mL}$, imersas em solução aquosa a $0,075 \%$ de concentração do sal 2, 3, 5 trifenil cloreto de tetrazólio e expostas à temperatura de $41{ }^{\circ} \mathrm{C}$ durante 8 horas. Após este período de coloração, as sementes foram lavadas em água corrente e cortadas longitudinalmente com um bisturi, ao longo do eixo embrionário, de modo a permitir a visualização do mesmo e dos cotilédones.

Foram consideradas sementes não viáveis aquelas que apresentaram tecido não colorido, flácido ou necrosado acima de 1/3 da extremidade da radícula, 1/3 dos cotilédones da região oposta do eixo hipocótilo radícula ou ao longo da borda do cotilédone, de acordo com a recomendação para Brassica spp. 
(BRASIL, 2009). Foram consideradas sementes viáveis aquelas com o embrião completamente colorido, ou quando parcialmente coloridos, apresentaram um gradiente de cor uniforme, mais intenso da periferia para o centro da semente (devido à penetração do sal na semente) e tecidos firmes com aparência uniforme.

A primeira contagem da germinação foi efetuada em conjunto com o teste de geminação, utilizando-se a mesma metodologia, calculando-se a porcentagem de plântulas normais obtidas no quarto dia após a semeadura (NAKAGAWA, 1999).

A emergência de plântulas foi realizada utilizando 200 sementes por tratamento, distribuídas em quatro repetições de 50 sementes, semeadas em bandejas de poliestireno (isopor) com 128 células individuais, contendo substrato comercial Bioplant. As bandejas foram mantidas em casa de vegetação, sob temperatura ambiente, e o subtrato irrigado diariamente. As avaliações foram realizadas aos 12 dias após a semeadura (período estabelecido em ensaios preliminares por considerar a emergência das plântulas de crambe estabilizada) por meio da contagem de plântulas que apresentavam os cotilédones abertos acima da superfície do solo, de acordo com os critérios adotados para avaliação da parte aérea de plântulas em um teste de germinação (BRASIL, 2009).

O índice de velocidade de emergência foi determinado durante a condução do teste de emergência de plântulas, por meio de contagens diárias das plântulas normais emergidas. O índice de velocidade de emergência foi obtido pela fórmula proposta por Maguire (1962), e os resultados foram expressos em índice médio de velocidade de emergência:

$\mathrm{IVE}=\mathrm{E} 1 / \mathrm{N} 1+\mathrm{E} 2 / \mathrm{N} 2+\ldots . .+\mathrm{En} / \mathrm{Nn}$, onde:

IVE: índice de velocidade de emergência

\section{E1, E2, ....., En: número de plântulas normais}

$\mathrm{N} 1, \mathrm{~N} 2, \ldots . ., \mathrm{Nn}$ : número de dias a partir da aprimeira contagem

Para o teste de condutividade elétrica foram utilizadas quatro repetições de 100 sementes, pesadas e colocadas em copos de plástico com capacidade para $200 \mathrm{~mL}$, contendo $50 \mathrm{~mL}$ de água deionizada, e mantidas em câmara à temperatura de $20{ }^{\circ} \mathrm{C}$, durante 16 horas, de acordo com a metodologia recomendada para canola (WAGNER; DUCOURNAU, 2007). As sementes utilizadas neste teste foram selecionadas quanto à presença do pericarpo.

Os dados obtidos foram submetidos à análise de variância e ao teste de Levenne, e as médias comparadas pelo teste de Tukey a 5\% de probabilidade. A análise estatística foi realizada por meio do programa SAS. 


\section{RESULTADOS E DISCUSSÃO}

A Tabela I apresenta o teor de água das sementes no início e no fim do processo de secagem em cada método estudado, variando o inicial de 15,3 a $16,0 \%$ e o final de 5,6 a $11,6 \%$.

Tabela 1 - Dados médios do teor de água no início e ao fim dos processos de secagem em cada método, tempo de secagem (TS - horas) e velocidade de secagem (V - pontos percentuais por hora) das sementes de crambe.

\begin{tabular}{|c|c|c|c|c|}
\hline \multirow{2}{*}{ Tratamentos } & \multicolumn{2}{|c|}{ Teor de água (\%) } & \multirow{2}{*}{ TS (h) } & \multirow{2}{*}{$\mathrm{V}\left(\mathrm{pph}^{-1}\right)$} \\
\hline & Inicial & Final & & \\
\hline Sombra & 15,8 & 7,3 & 113 & 0,08 \\
\hline Ar aquecido & 16,0 & 6,4 & 6,6 & 1,46 \\
\hline Ar não aquecido & 15,9 & 5,6 & 113 & 0,09 \\
\hline Terreiro & 15,3 & 7,6 & 98 & 0,08 \\
\hline Planta & $* 19,9$ & 11,6 & 144 & 0,06 \\
\hline
\end{tabular}

* Teor de água aos 129 dias após a semeadura.

A secagem das sementes de crambe na planta foi a mais lenta comparada aos demais tratamentos (Tabela I), sendo que o teor de água inicial foi considerado o correspondente ao determinado aos 129 dias após a semeadura $(19,93 \%)$. O tempo de secagem deste tratamento foi de 144 horas para reduzir o teor de 19,93 para $11,57 \%$.

A maior velocidade média de secagem foi obtida no tratamento com ar aquecido, pois este reduziu o teor de água das sementes de 16,0\% para 6,4\% em 6,6 horas, ou seja, 1,46 $\mathrm{pph}^{-1}$ (Tabela 1). Além do teor de água das sementes e da temperatura, o tempo de exposição e a velocidade de secagem podem afetar a qualidade das sementes. A secagem artificial reduziu rapidamente o teor de água das sementes e não teve efeito imediato negativo sobre a germinação de sementes de crambe. A secagem à sombra, secagem artificial com ar não aquecido e a secagem em terreiro foram semelhantes quanto à velocidade média de secagem, sendo, respectivamente, de 0,08, 0,09 e 0,08 $\mathrm{pph}^{-1}$.

Costa et al. (2010) verificaram que os tempos de secagem das sementes de crambe, considerando a redução do teor de água de 20,0 para 8,2\%, nas temperaturas de $30,40,50,60$ e $70{ }^{\circ} \mathrm{C}$ e umidades relativas de 37,$4 ; 22,3 ; 14,0 ; 8,3$ e $5,1 \%$ foram 20,$5 ; 8,5 ; 5,0 ; 5,0 ;$ e 2,75 horas, respectivamente.

As sementes de crambe apresentaram, em todos os tratamentos, baixa porcentagem de germinação, variando entre 3,62 a 5,75\% (Tabela 2). A porcentagem de sementes dormentes, verificada através do 
teste de tetrazólio ao final do teste de germinação, variou entre 83,12 a $88,75 \%$, mostrando que as sementes de crambe apresentam alto grau de dormência logo após a colheita.

Tabela 2 - Dados referentes à porcentagem de germinação, primeira contagem da germinação, plântulas anormais, sementes dormentes e sementes mortas, no teste de germinação dos tratamentos de secagem em sementes de crambe.

\begin{tabular}{ccccccc}
\hline \multirow{2}{*}{$\begin{array}{c}\text { Métodos de } \\
\text { secagem }\end{array}$} & \multirow{2}{*}{$\begin{array}{c}\text { Teor de } \\
\text { água (\%) }\end{array}$} & Germinação & $\begin{array}{c}\text { Primeira } \\
\text { contagem }\end{array}$ & $\begin{array}{c}\text { Sementes } \\
\text { dormentes }\end{array}$ & $\begin{array}{c}\text { Sementes } \\
\text { mortas }\end{array}$ & $\begin{array}{c}\text { Plântulas anor- } \\
\text { mais }\end{array}$ \\
\hline Sombra & 7,0 & $5,75 \mathrm{a}$ & $2,25 \mathrm{a}$ & $84,91 \mathrm{a}$ & $4,91 \mathrm{a}$ & $4,41 \mathrm{ab}$ \\
Ar aquecido & 7,1 & $3,62 \mathrm{a}$ & $1,12 \mathrm{a}$ & $83,12 \mathrm{a}$ & $6,12 \mathrm{a}$ & $7,12 \mathrm{a}$ \\
Ar não aquecido & 7,3 & $4,83 \mathrm{a}$ & $1,50 \mathrm{a}$ & $86,58 \mathrm{a}$ & $5,50 \mathrm{a}$ & $3,08 \mathrm{~b}$ \\
Terreiro & 7,2 & $4,08 \mathrm{a}$ & $1,58 \mathrm{a}$ & $85,33 \mathrm{a}$ & $7,66 \mathrm{a}$ & $2,91 \mathrm{~b}$ \\
Planta & 7,3 & $4,75 \mathrm{a}$ & $1,83 \mathrm{a}$ & $88,75 \mathrm{a}$ & $2,50 \mathrm{~b}$ & $4,00 \mathrm{ab}$ \\
\hline C.V. (\%) & & 44,05 & 59,2 & 4,14 & 19,04 & 49,12 \\
\hline
\end{tabular}

Médias seguidas da mesma letra na coluna não diferem entre si pelo teste de Tukey a 5\% de probabilidade.

O crambe foi introduzido no Brasil pela Fundação Mato Grosso do Sul, que trouxe materiais vindos do México, os quais foram selecionados pelos pesquisadores, originando a primeira cultivar de crambe (FMS Brilhante) no país (PITOL; BROCH; ROSCOE, 2010). A alta porcentagem de sementes recémcolhidas dormentes evidencia a necessidade de maiores estudos e melhoramento genético desta planta, para que seja possível obter sementes capazes de germinar logo após a colheita. Espécies cujas sementes apresentam dormência representam um problema para a produção de sementes, visto a dificuldade em determinar a qualidade do lote para comercialização.

As condições ambientais em que as sementes foram produzidas neste experimento também podem ter favorecido a dormência. A dormência é uma característica herdada que é intensamente modificada pelo ambiente durante a formação da semente (LAWRENCE; MCDONALD, 2001). A expressão da hereditariedade de uma semente na forma de germinação depende do ambiente durante a formação da semente, maturidade e dos variáveis bloqueadores de germinação (DESAI, 2004).

Nas condições realizadas neste trabalho os tratamentos não apresentaram diferença significativa dos demais tratamentos quanto à porcentagem de germinação e vigor, verificado pela primeira contagem da germinação das sementes de crambe avaliadas imediatamente após a secagem. Em sementes de canola (Brassica napus L.), Corrêa, Martins e Christ (1999), verificaram que a combinação da temperatura e da 
umidade relativa do ar de secagem afeta o vigor e a germinação. Estudando as temperaturas 30, 40, 50 e $60{ }^{\circ} \mathrm{C}$ e umidade relativa de 30, 40, 50 e $60 \%$ do ar de secagem, os autores concluíram que a combinação da temperatura de $30{ }^{\circ} \mathrm{C}$ e $60 \%$ de umidade relativa do ar resultou nas maiores taxas de germinação e vigor.

Não houve diferença significativa entre os tratamentos de secagem estudados quanto à primeira contagem e à porcentagem de germinação. Isto mostra que as sementes de crambe podem ser colhidas com teor de água elevado (18 a 20\%) e serem submetidas a métodos de secagem artificial, sem prejuízo imediato à germinação, ou podem ser mantidas no campo até que a umidade das sementes seja reduzida naturalmente.

A maior porcentagem de plântulas anormais foi obtida no tratamento de secagem com ar aquecido $(7,12 \%)$. Em todos os tratamentos de secagem, havendo influência da dormência sobre a germinação, parte da porcentagem de plântulas anormais incluiu sementes germinadas tardiamente, ou seja, sementes que apenas emitiram raíz primária.

Não houve influência do método de secagem na superação ou maior indução de dormência nas sementes de crambe, pois apesar da alta porcentagem de sementes dormentes, não houve diferença significativa entre os métodos de secagem estudados.

A secagem na planta apresentou menor porcentagem de sementes mortas quando comparado aos demais tratamentos. A época de colheita pode ser o fator que contribuiu para esta diferença, pois a primeira colheita incluiu os tratamentos de secagem à sombra, secagem com ar não aquecido, secagem com ar aquecido e secagem em terreiro. Desta forma, a primeira colheita pode ter resultado em maior número de sementes imaturas retiradas da planta-mãe, que podem não ter adquirido tolerância à dessecação, afetando a viabilidade das sementes. Na mostarda (Sinapis alba L.), pertencente à mesma família do crambe, a tolerância à dessecação a conteúdos de água baixos (5\% ou menos) aumenta no final do processo de desenvolvimento da semente (FISCHER et al., 1988 citado por ELLIS; HONG, 1994).

Quanto às sementes mortas, fato semelhante ao ocorrido neste experimento foi observado por Nakagawa, Cavariani e Zucareli (2005) em sementes de mucuna-preta colhidas em diferentes dias e secadas fora da vagem. Os autores verificaram que houve predominância de sementes mortas nas primeiras colheitas e que esta diminuiu nas colheitas seguintes com o aumento das sementes duras, das plântulas normais e anormais. Portanto, provavelmente, nas primeiras colheitas predominavam as sementes em estádio de intolerância à dessecação e, com o desenvolvimento, as sementes passaram a tolerantes, as quais resultaram sementes duras ou que germinaram.

Na Tabela 3 estão apresentados os resultados dos testes de condutividade elétrica, emergência de plântulas e índice de velocidade de emergência. 
Tabela 3 - Resultados da condutividade elétrica, emergência de plântulas e índice de velocidade de emergência de plântulas dos tratamentos de secagem em sementes de crambe.

\begin{tabular}{cccc}
\hline Tratamentos & $\begin{array}{c}\text { Condutividade Elétrica } \\
(\mu \mathrm{S} / \mathrm{cm} / \mathrm{g})\end{array}$ & $\begin{array}{c}\text { Emergência de Plântulas } \\
(\%)\end{array}$ & IVE \\
\hline Sombra & $128,6 \mathrm{a}$ & $8,75 \mathrm{a}$ & $0,69 \mathrm{a}$ \\
Ar aquecido & $144,32 \mathrm{a}$ & $6,12 \mathrm{a}$ & $0,48 \mathrm{a}$ \\
Ar não aquecido & $138,62 \mathrm{a}$ & $6,66 \mathrm{a}$ & $0,53 \mathrm{a}$ \\
Terreiro & $127,44 \mathrm{a}$ & $7,83 \mathrm{a}$ & $0,59 \mathrm{a}$ \\
Planta & $122,97 \mathrm{a}$ & $8,50 \mathrm{a}$ & $0,66 \mathrm{a}$ \\
\hline C.V. $(\%)$ & 11,21 & 30,86 & 31,49 \\
\hline
\end{tabular}

Médias seguidas da mesma letra na coluna não diferem entre si pelo teste de Tukey a 5\% de probabilidade.

O teste de condutividade elétrica não detectou diferença na qualidade dos tratamentos de secagem. Deve ser considerada no teste de condutividade elétrica em sementes de crambe a presença do pericarpo, que não permite que as sementes fiquem completamente submersas na solução de embebição, ou seja, as sementes de crambe, quando colocadas na água, flutuam.

Não houve diferença entre os métodos de secagem estudados quanto à emergência de plântulas, e da mesma maneira, o índice de velocidade de emergência não apresentou diferença significativa entre os tratamentos.

De acordo com os resultados, os métodos de secagem estudados não causaram efeito imediato na qualidade das sementes de crambe, que apresentaram elevada porcentagem de sementes dormentes após a colheita. A secagem na planta resultou em menor número de sementes mortas devido a colheita um pouco mais tardia, permitindo a obtenção de menos sementes imaturas.

\section{CONCLUSÕES}

Não houve efeito imediato negativo dos métodos de secagem à sombra, secagem com ar não aquecido, secagem com ar aquecido, secagem em terreiro e secagem no campo sobre a qualidade de sementes de crambe.

O método de secagem na planta proporcionou menor número de sementes mortas em relação aos demais tratamentos.

As sementes de crambe apresentaram alto grau de dormência após a colheita. 


\section{REFERÊNCIAS}

BRASIL. Ministerio da Agricultura. Departamento Nacional de Producao Vegetal. Regras para Análise de Sementes. Brasilia, DF, 1992. 365 p.

BRASIL. Ministério da Agricultura, Pecuária e Abastecimento. Regras para análise de sementes. Brasília, DF, 2009. 399 p.

CASTRO, R. D.; BRADFORD, K. J.; HILHORST, H. W. M. Desenvolvimento de sementes e conteúdo de água. In: FERREIRA, A.G.; BORGUETTI, F. Germinação: do básico ao aplicado. Porto Alegre: Artmed, 2004. p. 51-67.

CARVALHO, N. M.; NAKAGAWA, J. Sementes: ciência, tecnologia e produção. 4. ed. Jaboticabal: FUNEP, 2000. 588 p.

CHRIST, D.; CORRÊA, P. C.; ALVARENGA, E. M. Efeito da temperatura e da umidade relativa do ar de secagem sobre a qualidade fisiológica de sementes de canola (Brassica napus L. var. oleifera Metzg.). Revista Brasileira de Sementes, Londrina, v. 19, n. 2, p.150-154, 1997.

COPELAND, L. O. Principles of seed science and technology. Minneapolis, Burgess, 1976. $369 \mathrm{p}$.

CORREAA, P. C.; MARTINS, A. J. H.; CHRIST, D. Thin layer drying rate and loss of viability modelling for rapeseed (canola). Journal of Agricultural Engineering Research, Karaj, v. 74, n. 1, p. 33-39, 1999. Disponível em: < http://www.sciencedirect.com/science/article/B6WH145GMGGP-1F/2/3d7a15f3808f61e6fd9026b8ccc6932d>. Acesso em 25 out. 2010.

COSTA, L. M., et al. Modelagem matemática de secagem de sementes de crambe. In: CONGRESSO DA REDE BRASILEIRA DE TECNOLOGIA DE BIODIESEL: BIODIESEL: INOVAÇÃO TECNOLÓGICA E QUALIDADE, 4., CONGRESSO BRASILEIRO DE PLANTAS 
OLEAGINOSAS, ÓLEOS, GORDURAS E BIODIESEL, 7., 2010, Belo Horizonte.

Anais...Lavras:UFLA, 2010. P. 641-642.

DESAI, B. B.; KOTECHA, P.M.; SALUNKHE, D. K. Seeds Handbook: Biology, prodution processing and storage. New York: Marcel Dekker., 1997. 627 p.

DESAI, B. B. Seeds handbook: Biology, prodution, processing and storage. 2. ed. New York: Marcel Dekker., 2004.787 p.

ELLIS, R. H.; HONG, T. D. Desiccation tolerance and potential longevity of developing seeds of rice (Oryza sativa L.). Annals of Botany, v.73, p. 501-506, 1994.

FONTANA, F. et al. Agronomic characterization of some Crambe abyssinica genotypes in a locality of the Po Valley. European Journal of Agronomy, Amsterdam, v. 9, p. 117-126, 1988. Disponível em: <http://www.ingentaconnect.com/content/els/11610301/1998/00000009/00000002/art00037>. Acesso em: 1 jul. 2010.

HAY, F. R.; PROBERT, R. J. Seed maturity and the effects of different drying conditions on desiccation tolerance and seed longevity in foxglove (Digitalis purpurea L.). Annals of Botany, Exeter, v. 76, p. 639-647, 1995. Disponível em:

$<$ http://aob.oxfordjournals.org/content/76/6/639.full.pdf+html?sid=e60bd318-906c-42b4-89770eb791d57416>. Acesso em: 25 out. 2010

JUSTICE, L. O.; BASS, N. L. Principles and practices of seed storage. In: MILLER, E. K. USDA agriculture handbooks: numbers 1-690. Agriculture Handbook No. 506. United States Department of Agriculture. 1978. n. 506, 298 p.

LAWRENCE, O. C; MCDONALD M. B. Principles of seed science and technology. 4. ed. Boston: Kluwer academic Publishers, 2001. 467 p.

MAGUIRE, J. D. Speed of germination aid in selection and evaluation for seedling emergence and vigor. Crop Science, Madison, v. 2, n. 2, p. 176-177, 1962. 
MARCOS FILHO, J. Fisiologia de sementes de plantas cultivadas. Piracicaba: FEALQ, 2005. 495 p.

NAKAGAWA, J. Testes de vigor baseados no desempenho das plântulas. In: KRZYZANOSKI, F. C.; VIEIRA, R. D.; FRANÇA NETO, J. B. Vigor de sementes: conceitos e testes. Londrina: ABRATES, 1999. p.2.1-2.24.

NAKAGAWA, J.; CAVARIANI, C.; ZUCARELI, C. Maturação, formas de secagem e qualidade fisiológica de sementes de Mucuna-preta. Revista Brasileira de Sementes, Londrina, v. 27, n. 1, p.45-53, 2005.

PITOL, C.; BROCH, D. L.; ROSCOE, R. Tecnologia e produção: crambe. Maracaju: Fundação MS, 2010. 60 p.

WAGNER, M. H.; DUCOURNAU, S. Conductivity testing for oilseed rape seeds. ISTA News Bulletin, n. 133, Apr., 2007. Disponível em:

<http://www.seedtest.org/upload/cms/user/STI133April2007.pdf>. Acesso em: 25 out. 2010. 